Are people more prejudiced towards groups that are perceived as coherent? A meta-analysis of the relationship between out-group entitativity and prejudice

\author{
Elena R. Agadullina \\ School of Psychology \\ National Research University Higher School of Economics \\ Moscow, Russia \\ Andrey V. Lovakov \\ Center for Institutional Studies \\ National Research University Higher School of Economics \\ Moscow, Russia
}

\title{
In press
}

British Journal of Social Psychology

DOI: 10.1111/bjso.12256

Address correspondence to Elena Agadullina, School of Psychology, National Research University Higher School of Economics, 20 Myasnitskaya Ulitsa, Moscow 101000, Russia. E-mail: eagadullina@hse.ru.

\section{Acknowledgment}

We thank Daniel Effron, Arne Roets, Anna Newheiser for providing the additional data for this meta-analysis. We also thank Matvey Lovakov for support and inspiration. The paper was prepared within the framework of the Basic Research Program at the National Research University Higher School of Economics (HSE), and supported within the framework of a subsidy by the Russian Academic Excellence Project '5-100'. 


\begin{abstract}
A meta-analysis was conducted to examine the relationship between out-group entitativity and prejudice. A quantitative analysis of 85 effect sizes from 33 independent samples showed a significant positive relationship between entitativity and prejudice (Fisher's $z=.414,95 \%$ CI $[.272, .557], p<.0001$ ). Three possible moderators of the relationship between entitativity and prejudice were tested: conceptualization of the entitativity (essence-based entitativity scale, agency-based entitativity scale, common entitativity scale), the target of the prejudice, the measures of prejudice (attitudes, emotions, behavior towards out-group). Results demonstrated that out-group entitativity correlated with prejudice only when entitativity was conceptualized as an essence-based or common-based scale, and prejudice was measured as the attitude to the out-group. The target of prejudice does not moderate the relationship between entitativity and prejudice.
\end{abstract}

Keywords: entitativity, prejudice, meta-analysis, robust variance estimation 


\section{Introduction}

Prejudice is a fundamental and central concept in social psychology that describes an attitude toward an out-group. Understanding the nature and predictors of prejudice is key to solving a host of social problems, especially in intergroup relations. Traditionally, the relatively stable personality dispositions (e.g., Big five), ideological attitudes (right wing authoritarianism, social dominance orientation) (Onraet et al., 2015; Sibley \& Duckitt, 2008) and social identification (Tajfel \& Turner, 1986) are regarded as the key predictors of prejudice. However, researchers concluded that personality dispositions alone cannot explain the complex nature of prejudices, and additional factors have to be considered. In particular, they assumed that the lay theories/beliefs about groups may be at least equally important for understanding prejudice (Hamilton, Sherman, \& Castelli, 2002). The most popular concept describing the lay theories about group perception is entitativity (Campbell, 1958). Lickel et al. (2000) defined entitativity as the 'degree to which a collection of persons are perceived as being bonded together into a coherent unit' (p. 224). Previous studies showed that entitativity plays a significant role in understanding the consequences of group perception, because when group entitativity is high, prejudice is stronger (e.g., Newheiser, Tausch, Dovidio, \& Hewstone, 2009). The intergroup relations, especially comparisons between ingroup and out-group, can actualize feelings of physical or social threats (threats to identification, status and the existing social hierarchy) and group entitativity can increase this feeling. Dasgupta, Banaji, and Abelson (1999) demonstrated that high out-group entitativity associated with 
perception of the out-group as threatening, dangerous and malevolent can in turn increase prejudice towards it.

During the last 20 years it has been confirmed that high out-group entitativity is frequently connected with negative outcomes, especially stereotyping (Levy, Plaks, Hong, Chiu, \& Dweck, 2001; Rydell, Hugenberg, Ray, \& Mackie, 2007; SpencerRodgers, Hamilton, \& Sherman, 2007; Spencer-Rodgers, Williams, Hamilton, Peng, \& Wang, 2007), racism (Andreychik \& Gill, 2015; Hodson \& Skorska, 2015; Keller, 2005; Roets \& Van Hiel, 2011), prejudice towards homosexuality (Gulevich, Osin, Isaenko, \& Brainis, 2016; Haslam \& Levy, 2006; Hodson \& Skorska, 2015), negative attitudes towards mental disorders (Haqanee, Lou, \& Lalonde, 2014; Hodson \& Skorska, 2015; Rüsch et al., 2009), attribution of blame to out-groups, willingness to punish them (Sherman \& Percy, 2010), and collective responsibility (Denson, Lickel, Curtis, Stenstrom, \& Ames, 2006; Lickel, Schmader, \& Hamilton, 2003). At the same time there are contrary findings that demonstrate entitativity is not associated with racism (Effron \& Knowles, 2015a; Haslam, Rothschild, \& Ernst, 2002), sexism (Haslam et al., 2002; Keller, 2005), and negative attitudes towards mental disorders (Haqanee et al., 2014; Rüsch et al., 2009). These contradictory results raise the first research question of our analysis. Research question 1: Does entitativity relate to prejudice?

The relationship between entitativity and prejudice may depend on several variables. We singled out three key and theoretically relevant moderators that may help to explain this relationship. First, because entitativity as a cognitive phenomenon exists primarily 'in the eye of the beholder' (Plaks, Levy, Dweck, \& Stroessner, 
2004), it is important how the authors conceptualize the group entitativity in their research. Second, the social groups vary in permeability of group boundaries, group size, group history and social status, which can lead to that they can be perceived less or more entitative. As a result, we can assume that the target of prejudice can moderate the relationship between entitativity and prejudice. Finally, in daily life prejudices can manifest themselves in different ways, from emotions and cognitions to intentions and behaviors. Therefore, the measure of prejudice can be considered as a moderator of the relationship between entitativity and prejudice.

The purpose of the current study is to examine comprehensively the relationship between entitativity and prejudice, focusing on key moderators of this relationship. Overall, the results of the meta-analysis enable us to fill in the gaps in the understanding of the nature of prejudice.

\section{Moderators}

\section{Conceptualization of entitativity}

Despite the fact that entitativity is a relatively new concept in social psychology there are several theoretical views relating to it. The authors allocate at least two different approaches to the understanding of group entitativity: the 'essence-based entitativity approach' and the 'agency-based entitativity approach' (Brewer, Hong, \& $\mathrm{Li}$, 2004). The essence-based entitativity approach considers similarity (homogeneity) in common attributes (e.g. physical features, personality traits etc.) as the key characteristics of entitativity. In particular, according to this approach high homogeneity is associated with greater entitativity (Askevis-Leherpeux, 2005; 
Crump, Hamilton, Sherman, Lickel, \& Thakkar, 2010). The most commonly used scale describing the essence-based approach was proposed by Haslam, Rothschild and Ernst (2000, 2002). The authors described nine elements of essentialism (immutability, inherence, discreteness, uniformity, naturalness, informativeness, exclusivity, necessity, stability) separated by two factors: 'natural kind' and 'entitativity'. The first factor includes beliefs that a social category is natural and has a clear boundary, essential features, immutability and historical invariance. The second factor includes the beliefs about an underlying, inherent nature of social category, informativeness of social categories, homogeneity of group members, and representation that the category doesn't include members from other categories.

The 'agency-based entitativity approach' focuses on the group members' heterogeneity and activity, and takes into account the group's motivations, intentions and level of interaction among group members (Brewer et al., 2004; Levy et al., 2001). According to this approach, the interaction between a group's members to achieve the group's goals is regarded as the most significant predictor of entitativity. Gaertner and Schopler (1998) experimentally manipulated the level of interaction between team members in competition and demonstrated that groups with an intensive level of interaction were assessed as being more entitative. At the empirical level, this approach is implemented through questions about the interaction and interdependence of group members, and the motivations and intentions of groups (Effron, 2015; Effron \& Knowles, 2015a; Stenstrom, Lickel, Denson, \& Miller, 2008). 
At the same time, the method combining both the essence-based and agencybased entitativity approaches is quite popular among researchers (Newheiser \& Dovidio, 2012; Newheiser et al., 2009; Ommundsen, Yakushko, Veer, \& Ulleberg, 2013; Phelps, Ommundsen, Türken, \& Ulleberg, 2013; Roets \& Van Hiel, 2011). In this case, the researchers use a set of characteristics from both views on entitativity. So, Lickel with colleagues (2000) described eight group characteristics related to entitativity: interaction among group members, importance of group membership, group goals, group outcomes, similarity among group members, permeability of group boundaries, group size, and duration. Newheiser with colleagues $(2012,2009)$ based on Lickel et al. (2000) developed an index for perceived entitativity that included questions on issues such as the interaction of group members, the importance of being a group member, the degree to which the group qualifies as a real group, and the similarity of group members. This index is a good example of a common scale of group entitativity.

Agadullina and Lovakov (2017) have shown that different conceptualizations of entitativity are associated with prejudice but the strength of this link is different. These findings may indicate that a way to conceptualize the group entitativity can moderate the relationship between entitativity and prejudice. In particular, the conceptualization of the group entitativity as the essence-based (but not as the agency-based) could increases the perception of out-group homogeneity that in turn could increase the prejudice towards out-group (Judd, Park, Yzerbyt, Gordijn, \& Muller, 2005; Simon et al., 1990). On the other hand, conceptualization the group entitativity as intensity of group members' interaction and sharing of group goal 
(agency-based entitativity) could lead to attribution of malicious intentions for outgroup and thus increase the prejudice.

The existence of the different approaches to understanding group entitativity and the various ways of it conceptualization brings us to the formation of the second research question. Research question 2: Does the conceptualization of entitativity moderate the relationship between entitativity and prejudice?

\section{Target of the prejudice}

There are a huge number of different social groups and their nature may be very different. Lickel with colleagues (2000), using empirical evidence, proposed to divide the groups into four large clusters: intimacy groups (e.g., family, close friends), task groups (e.g., sports teams), social categories (e.g., race/ethnic, gender) and loose association (e.g., people at the bus stop). Different social categories are the most common targets of prejudice. Demoulin, Leyens, and Yzerbyt (2006) suggested that social categories can be divided into forced social categories (such as gender, ethnicity, race) and chosen social categories (e.g., religious or professional groups). The perception of forced social categories is based on the belief in the genetic/biological basis of group properties and identity. In other words, people believe that sets of genes determine whether someone belongs to a gender or racial group and this group membership cannot be changed. In the case of chosen social categories, groups' properties are viewed as the result of group activity and personal responsibility. Studies showed that forced social categories are evaluated as being 
higher in entitativity than chosen social categories (Haslam et al., 2000; Prentice \& Miller, 2007). As a result, we can expect that prejudice towards forced social categories will be higher compared with chosen social categories. In support of these assumption, the studies showed that prejudice toward different chosen categories (e.g., religious groups such as Muslims) (Effron, 2015; Effron \& Knowles, 2015a), and professional groups (e.g., teachers or scientists) (Effron \& Knowles, 2015a) is weak or absent, while prejudice against forced social categories (e.g., ethnic/racial groups (Andreychik \& Gill, 2015; Hodson \& Skorska, 2015; Roets \& Van Hiel, 2011), gays and lesbians (Gulevich et al., 2016; Hodson \& Skorska, 2015; van Rijswijk, Haslam, \& Ellemers, 2006) and people with mental illnesses (e.g., schizophrenia) (Haqanee et al., 2014; Hodson \& Skorska, 2015)) is strong. At the same time, the opposite results were obtained by Brickman (2009), who demonstrated that the belief that people choose groups of memberships themselves was significantly positively correlated with prejudice against gay men, lesbians, criminals, evangelical Christians, and poor Whites. These contradictory findings may indicate that the type of social category could moderate the relationship between entitativity and prejudice.

In addition, previous works revealed that different social groups (even if they belong to the same social category, for instance, to the forced social category) might also differ in their level of entitativity. So, gender groups were perceived as more entitative than ethnic groups (Haslam et al., 2000). Based on these results, we may assume that the target group for which the prejudice is assessed (e.g., race/ethnic group, etc.) can also moderate the relationship between entitativity and prejudice. 
In summary, these results allowed us to formulate the third research question of our study. Research question 3: Does the type of social category (forced or chosen)) and the target group (e.g. race/ethnic group, etc.) moderate the relationship between entitativity and prejudice?

\section{Measures of prejudice}

Prejudice is a complex social phenomenon that is more often defined as an attitude (in particular, negative) toward people based on their membership in a group (see for example, Baumeister \& Vohs, 2007 p. 694). Attitudes towards out-groups could be manifested in different ways such as negative emotions to out-group members, attitudes towards out-group, and discriminatory behavior. Because prejudices can manifest themselves in various forms and different social groups could be targets of prejudice, a variety of scales and ways to measure the prejudice have been developed over the past few decades. Smith, Axelton, and Saucier, (2009) in their meta-analysis related to sexual prejudice, demonstrated that standardized prejudice scales (e.g., the Attitudes to Lesbians and Gay Men Scale by Herek (1984)) showed the strongest relationship between contact and sexual prejudice compared with the original researchers' scales. Miles and Crisp (2013), having studying the imagined contact effects on four measures of prejudice (attitudes, emotions, intentions, and behavior), showed that the effect was stronger on behavioral intentions than on attitudes. These findings demonstrated that the type of prejudice measure could influence the study results. We assumed that the prejudice measure could also moderate the relationship between entitativity and prejudice. The 
entitativity arises from the perception of the group characteristics, which can actualize different stereotypes and attitudes but to a lesser extent can associate with specific discriminatory behavior. In fact, previous studies have shown that entitativity (especially within the essence-based approach) significantly predicted one type of prejudices (e.g., the formation of stereotypes, attitudes towards the group (Crawford, Sherman, \& Hamilton, 2002; Rydell et al., 2007; Spencer-Rodgers, Hamilton, et al., 2007) and discriminatory behaviors (Phelps et al., 2013)), while it was not always related to another types (e.g., emotions towards out-group (Agadullina, 2015; Effron, 2015; Effron \& Knowles, 2015a)). These findings led us to the formulation of the fourth research question. Research question 4: Does the measure of prejudice moderate the relationship between prejudice and entitativity?

\section{Additional moderators (study characteristics)}

In addition to examining the main moderators, we also identify and analyze other possible sources of variability in the relationship between entitativity and prejudice. In our analysis, we consider the type of sample (general population or college students), the geographic location of the sample and the study design (experiment or cross-sectional study).

\section{Method}

\section{Literature search}

To identify all possible studies, four steps were taken. First, computer-based literature searches were completed in Google Scholar, Web of Science, and the Scopus 
database for studies published before March 15, 2017. Search terms included combinations of the following key words: entitativity, groupness, prejudice, bias, out-group attitude (including the hyphenated out-group), ingroup favoritism (including the hyphenated in-group), stereotype and discrimination. Next, we conducted a search in ProQuest Dissertations and Theses using the same search terms. For step three, we contacted researchers who have published relevant studies by email to request unpublished or in-press work. In total, 26 emails were sent. Finally, for the fourth step, to ensure that our search included all relevant studies we examined references in review articles and meta-analyses that focused on prejudice (Sibley \& Duckitt, 2008; Smith et al., 2009), and entitativity (Boldry, Gaertner, \& Quinn, 2007; V. Y. Yzerbyt, Judd, \& Corneille, 2004).

In all, we identified 213 documents, including papers, theses, and unpublished works. The first author performed the literature searches, while both authors independently reviewed titles and abstracts from the list of potentially relevant studies. The full text of each study was examined to see whether it could be included.

\section{Rules for inclusion and exclusion in the meta-analysis}

We included studies in meta-analysis if they met the following criteria (Figure 1 illustrates the final inclusion flow chart):

Criterion 1. Studies must include measures of prejudice and out-group entitativity evaluation. We did not include studies where one of the variables was missing (Askevis-Leherpeux, 2005; Bangerter, 2005; Castano, Yzerbyt, \& Bourguignon, 2003). We also did not include in the analysis studies where ingroup 
entitativity was measured (e.g., Roets \& Van Hiel, 2011 study 1b; Sacchi, Castano, \& Brauer, 2009 study 1,3). The studies with gender groups or results related to gender group as the target of prejudice were also excluded, because the samples in these studies included both men and women, and it is impossible to determine how the ingroup or out-group entitativity was measured (e.g., Haslam et al., 2002; Keller, 2005).

Criterion 2. Studies must include relevant correlations, effect sizes, or enough statistical information to calculate effect sizes. The theoretical papers (e.g. Brown, 2000; Haslam, 2003) and studies that used interviews as a research method were not included (e.g. Hughey, 2010).

Criterion 3. The different social categories must be targets of the prejudice. If the studies contained the results for other types of group (task group or intimacy groups), we coded only the results relating to social categories (Spencer-Rodgers, Hamilton, et al., 2007). We did not include the experimental/fictional group (e.g., Dasgupta et al., 1999).

Criterion 4. The same results must be considered only once. When a doctoral dissertation or conference thesis and a published study reported the same data, we included only the published study (Newheiser, 2012; Newheiser et al., 2009).

Criterion 5. Studies must be published in English. The studies that have been published in Spanish (Pereira, Alvaro, \& Garrido, 2016; Pereira, Álvaro, Oliveira, \& Dantas, 2011; Ramirez, Uruena, \& Moreno, 2012; Sáez, 1993) or in Japanese (Futaki, Watanabe, Sakurai, \& Karasawa, 2016) were not included. 


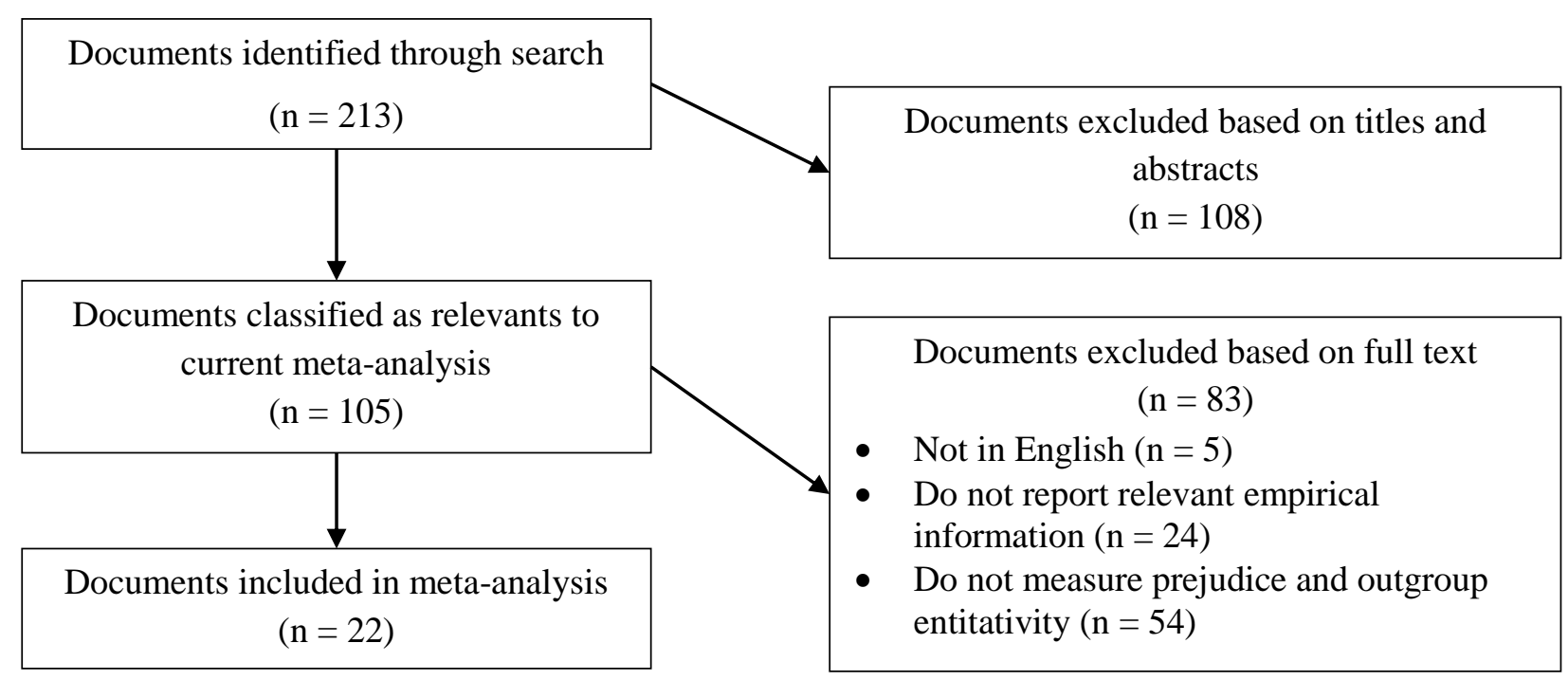

Figure 1. Documents inclusion flow chart.

\section{Coding procedures}

If available, the following information from each study was recorded: (a) author/s;

(b) publication year; (c) number of participants; (d) number of women among participants; (e) type of sample (general population/students); (f) country data collection (location) (if the country of data collection was not clear, the decision was made in accordance with the affiliation of the first author); (g) study design (experiment/cross-sectional); (h) information about correlations were extracted if possible; if there was no information about correlations in the article, other relevant statistics were extracted (Cohen's $d, \eta^{2}, F$ statistics, the mean and standard deviation for the relevant scales, standardized regression coefficient); (i) publication status (published/unpublished). If the article provided information about Cronbach's alpha for entitativity and prejudice measurements, it also was recorded. If a study report rendered determining the necessary information impossible (e.g. Cronbach' alpha, etc.), the required variable was coded as 'missing data'. 
Conceptualization of entitativity. We divided the various measures relating to entitativity into three categories: an essence-based entitativity scale, an agency-based entitativity scale, and a common entitativity scale based on Brewer et al., (2004). If the article did not include detailed descriptions of entitativity measures, but referred to another article from which the measure was taken, the decision was made to classify the measure to a certain category based on this second article.

The measures of entitativity including only the items relating to similarities of group members or experimental procedures actualizing the entitativity by the similarity of group members or the measures based on Haslam et al., (2000) were coded as an 'essence-based entitativity scale'.

If entitativity was measured by the scale that included only the items about the interaction of group members, group goals and intentions, or appropriate experimental manipulation, the scale was coded as an 'agency-based entitativity scale' (Effron \& Knowles, 2015a; Stenstrom et al., 2008). If the entitativity measurement included both the items about similarities and interaction among group members (Newheiser \& Dovidio, 2012; Newheiser et al., 2009; Roets \& Van Hiel, 2011) or the measure was based on Lickel et al., (2000) the scale was coded as a 'common entitativity scale'.

Target of prejudice. The target groups were combined into: ethnic/racial group (which included groups based on race, ethnicity, or national origin), sexual orientation (gay men, lesbians, bisexual people), religion (Muslims, Christians), mental and somatic disorders (e.g., schizophrenia, addictions (alcoholism) and neurological disorders (Parkinson's disease)), and others (scientists, teachers, people 
from the same hometown, asylum seekers, persons without German citizenship, members of Republican or Democratic political parties, etc..). If the target of prejudice differed among respondents it was coded as 'missing data' (Stenstrom et al., 2008))

The type of social category was defined based on Demoulin et al., (2006). We divided the groups on forced and chosen social categories. Forced social categories included those groups that are perceived by laypeople as having deeply rooted biological grounds and inborn membership that cannot be changed (e.g., gender group, ethnic/racial group). Previous works demonstrated that mental and somatic disorders are perceived as innate, immutable, and discrete (Haqanee et al., 2014; Haslam et al., 2000), which is why these groups also were coded as forced social categories. Chosen social categories included those groups that are perceived as an individual choice (for example, religion group, professional group (scientist, teachers), etc.). The boundaries of such groups are permeable, allowing people to change their group membership should they desire. The category 'sexual orientation' was excluded because some people perceive sexual orientation as an innate feature and others see it as a result of individual choice (Haslam \& Levy, 2006; Horvath \& Ryan, 2003).

\section{Measures of prejudice}

Following Miles and Crisp (2013), we included in our analysis any measure related to prejudice and combined theirs into three categories: attitudes toward the group, emotions toward the group and behavior (including intended behavior) toward the group. 
The 'attitudes toward the group' category included the standardized measures of explicit attitudes combined with the cognitive and affective component of attitudes (e.g., for the sexual orientation group: the Attitudes to Lesbians and Gay Men Scale by Herek (1984); for the ethnic/racial group: the Blatant and Subtle Racism Scale by Pettigrew \& Meertens (1995), and the Attitudes Toward Blacks Scale by Brigham (1993), etc.; for mental disorders: the Attitudes toward Mental Disorder Scale by Tanaka, Inadomi, Kikuchi, \& Ohta (2004); and for the religion group: the Islamophobia Scale by Lee et al., (2013)). An attribution of positive and negative characteristics to groups (including stereotyping) (Newheiser et al., 2009; SpencerRodgers, Hamilton, et al., 2007) and rating the relationship between the participant and the out-group (e.g., social distance) (Gulevich et al., 2016) were also included in this category.

The 'emotions toward the group' category included ratings of intergroup emotions (e.g., anger, contempt, disgust) (Newheiser \& Dovidio, 2015; Stenstrom et al., 2008), measures of general positive or negative affect towards the group (Agadullina, 2016) and the results of Thermometer rating task (feeling thermometers) (Effron \& Knowles, 2015a).

The 'behavior (including the intended behavior) toward the group' category included measures of readiness for future interactions (e.g., willingness to support proactive integration) (Phelps et al., 2013) and of expectations from future interaction (e.g., attribution of responsibility and retribution) (Stenstrom et al., 2008), and motivation to be less prejudiced (Effron \& Knowles, 2015a). 
If the study included more than one measure of prejudice, the data for each measure were coded independently.

\section{Collecting of effect sizes}

Correlation coefficient $(r)$ was used as an effect size in the meta-analysis. For each study, we collected the correlation coefficient for the relationship between entitativity and prejudice. Effect sizes were recoded to reflect a direct relationship (a high level of entitativity, a high level of prejudice) if needed. When $r$ was not available, one of four computations were used: 1) transformation of Cohen's $d$ into $r$ (Formula 7.7, Borenstein, Hedges, Higgins, \& Rothstein, 2009), 2) transformation of $\eta^{2}$ into $r$ (Lenhard \& Lenhard, 2016), 3) calculation $r$ based on $F$ statistics, means, standard deviations and sample sizes using the compute.es package in R (Del Re, 2013), 4) transformation of the standardized regression coefficient into $r$ by $\beta$-to- $r$ imputation formula $r=\beta+.05 \lambda$, where $\lambda=1$ when $\beta$ is nonnegative and $\lambda=0$ when $\beta$ is negative (Peterson \& Brown, 2005).

\section{Meta-analysis procedure}

Correlation coefficients were corrected for measurement error. Following Hunter and Schmidt (2004), the individual correlation coefficient was divided by the square root of the reliability estimates (Cronbach's alpha) of the two correlated variables, when the reliability estimates were available. When reliabilities for scales were not reported or measures consisted of only a single item, the individual correlation coefficient was divided by the square root of the reliability estimates of only one correlated variable 
or was not corrected for measurement error. All correlation coefficients were transformed to the Fisher's $z$ scale prior to data analysis. Standard errors for all effect sizes were computed using the metafor package in R (Viechtbauer, 2010). Effect sizes and main characteristics of studies are shown in Appendix. The dataset is available at https://osf.io/aj5yf/.

An independent piece of research (sample) often contained more than one relevant effect size, thus the set of collected effect sizes were not independent. To deal with dependency across effect sizes and not reduce the power through calculating the average values for the effect sizes extracted from the same study (sample) the robust variance estimation (RVE) was used for meta-analysis (Hedges, Tipton, \& Johnson, 2010) via the robumeta package for R (Fisher \& Tipton, 2015).

To estimate the overall effect size, an intercept-only meta-regression model was run. The intercept of this model can be interpreted as the overall effect size. For all analyses, the in-study effect size correlation $(\rho)$ was set at .8. The sensitivity analyses were conducted across varying values of $\rho(.0, .2, .4, .6, .8,1.0)$ to check the robustness of the coefficient of meta-regression, standard error, and between-study variance in study-average effect sizes values.

The same approach was used to calculate mean effect sizes for each value of the moderator. Moderator analysis was also conducted via RVE meta-regression models, with moderator variables as predictors. Separate meta-regression models were run with each moderator variable as a predictor. This approach was used instead of one meta-regression model with predictors for all moderators, because two moderator variables are the different versions of the same moderator (target of the prejudice). 
Categorical moderators with two levels were dummy coded (e.g. forced group $=1$, chosen group $=0$ ); thus, the regression coefficient for this dummy-variable should be interpreted as a difference in effect size between two levels of the moderator. Categorical moderators with more than two levels were also dummy coded $(k-1$ dummy-variables), but the regression coefficient for these dummy-variables represents the difference in effect size between only two levels of the moderator (the reference and the single comparison levels). To test the difference among all levels of the moderator, the Wald_test function from the clubSandwich package (Pustejovsky, 2017) was used. This function conducts a Wald-type test of linear contrasts from a fitted linear regression model. A $F$-value indicates whether there is a difference among all levels of the moderator.

\section{Publication bias analysis}

To take into account the dependencies in the data analysis publication bias was conducted by PET (Precision-Effect Test) and PEESE (Precision-Effect Estimate with Standard Error) (Stanley \& Doucouliagos, 2014) metaregression with RVE via the robu function from the robumeta package (Fisher \& Tipton, 2015). These weighted regression models consider the relationship between effect size and its corresponding standard error (PET) or variance (PEESE). Because PET underestimates non-zero effects and PEESE overestimates null effects, a two-step conditional PET-PEESE procedure was used. If PET showed a significant effect, the PEESE estimate was used; if PET did not show a significant effect, the PET estimate 
was used (Stanley \& Doucouliagos, 2014). The mean effect sizes calculated based on published and unpublished studies were conducted as one more publication bias tests.

A number of standard and most common publication bias tests requiring independent structure of data were also conducted. Before conducting these tests, dependent effect sizes were aggregated via the agg function from the MAc package (Del Re \& Hoyt, 2012). Based on aggregated data, a funnel plot and a contourenhanced funnel plot were examined and four statistical tests of publication bias were performed: trim-and-fill (Duval \& Tweedie, 2000), PET, PEESE, and weightfunction modeling (Vevea \& Hedges, 1995).

\section{Results}

\section{Description of data set}

In total, we identified 33 independent samples from 22 documents, summarizing 85 effect sizes (2.6 effect sizes per independent sample) and data from more than 8,400 participants. All studies were conducted or published between 2002 and 2017. Main characteristics of the data set are described in Table 1 . The majority of studies were conducted in the United States, Belgium, Russia, Canada, and the United Kingdom. There were also samples from Germany, Poland, Norway, and Australia. More than half the studies were conducted on samples of students. The majority of identified effect sizes were extracted from published cross-sectional studies. There are all three types of conceptualizations of entitativity discussed above. 
Table 1. Characteristics of the data set

\begin{tabular}{|c|c|c|}
\hline & $\begin{array}{l}\text { Number of } \\
\text { independent samples }\end{array}$ & $\begin{array}{l}\text { Number of } \\
\text { effect sizes }\end{array}$ \\
\hline \multicolumn{3}{|l|}{ Conceptualization of entitativity } \\
\hline Agency-based & 10 & 14 \\
\hline Common scale & 16 & 43 \\
\hline Essence-based & 10 & 28 \\
\hline \multicolumn{3}{|l|}{ Target of the prejudice (social categories) } \\
\hline Chosen group & 13 & 23 \\
\hline Forced group & 23 & 55 \\
\hline \multicolumn{3}{|l|}{ Target of the prejudice (target group) } \\
\hline Ethnic/racial group & 20 & 45 \\
\hline Mental and somatic disorders group & 2 & 7 \\
\hline Religion group & 6 & 13 \\
\hline Sexual orientation group & 5 & 7 \\
\hline Other & 7 & 11 \\
\hline \multicolumn{3}{|l|}{ Measure of prejudice } \\
\hline attitudes toward the group & 27 & 70 \\
\hline behavior toward the group & 3 & 3 \\
\hline emotions toward the group & 9 & 12 \\
\hline \multicolumn{3}{|l|}{ Location } \\
\hline Australia & 1 & 4 \\
\hline Belgium & 5 & 13 \\
\hline Canada & 3 & 11 \\
\hline Germany & 1 & 3 \\
\hline Norway & 2 & 4 \\
\hline Poland & 1 & 4 \\
\hline Russia & 4 & 18 \\
\hline UK & 3 & 7 \\
\hline USA & 13 & 21 \\
\hline \multicolumn{3}{|l|}{ Sample Type } \\
\hline General population & 16 & 39 \\
\hline Students & 17 & 46 \\
\hline \multicolumn{3}{|l|}{ Study design } \\
\hline Cross-sectional & 24 & 71 \\
\hline Experiment & 9 & 14 \\
\hline \multicolumn{3}{|l|}{ Published/Unpublished } \\
\hline Published & 27 & 69 \\
\hline Unpublished & 6 & 16 \\
\hline
\end{tabular}




\section{Overall effect}

The estimate of the mean effect size (Fisher's $z$ ) between entitativity and prejudice for all studies was $.414(S E=.070, t=5.92, d f=32.0, p=.00000136,95 \%$ CI [.272, .557]), indicating a moderate and non-zero positive effect. The sensitivity analysis shows that $\tau^{2}$, and subsequently the average effect size, are robust to different values of the within-study effect size correlation. However, the $I^{2}=97.26$ indicates that most of the observed variance in effect sizes was not due to chance. Differences in effect size due to moderator variables were investigated.

\section{Moderator analysis}

Results of the all separate meta-regressions with moderator variables as predictors are shown in Table 2. Mean effect sizes for each value of the moderators are shown in Table 3 and Figure 2.

Conceptualization of the entitativity (essence-based scale, agency-based scale or common scale)

There were differences in effect sizes between different types of conceptualization of the entitativity $(F(19.8)=9.27, p=.001)$. As shown in Table 3 and Figure 2a, mean effect sizes were positive and moderate when entitativity was conceptualized by a common scale $(\mathrm{ES}=.537,95 \%$ CI $[.328, .747])$ and by an essence-based approach $(\mathrm{ES}=.601,95 \% \mathrm{CI}[.426, .776])$, whereas in cases where entitativity was conceptualized by an agency-based approach, mean effect size was indistinguishable from zero (ES $=.121,95 \% \mathrm{CI}[-.128, .370])$. 
The target of the prejudice

The target of the prejudice defined by the forced or chosen type of social category was not a significant predictor of effect size $(b=-.052,95 \%$ CI $[-.375$, $.270], p=.740$ ). Mean effect sizes were comparable when the forced social category was a target of the prejudice $(\mathrm{ES}=.365,95 \% \mathrm{CI}[.199, .530])$ and when the chosen social category was a target of the prejudice $(\mathrm{ES}=.410,95 \%$ CI $[.133, .687])$. More detailed identification of the target of the prejudice also did not show the effect of this moderator. There were no differences in effect sizes between different target groups (ethnic/racial group, sexual orientation group, religion group, other groups) $(F(8.03)=1.02, p=.433)$. See Table 3 for exact mean size effects for different target groups.

Measure of prejudice (attitudes, behavior, emotions)

An $F$-test showed that there were no significant differences in effect sizes between different measures of the prejudice $(F(3.7)=6.23, p=.065)$. However, intercept-only meta-regression models for each type of the measure of prejudice showed that for measures based on attitudes towards the group, mean effect size was moderate $(\mathrm{ES}=.477,95 \%$ CI $[.315, .640])$, whereas for measures based on emotions towards the group, mean effect size was indistinguishable from zero (ES $=.133,95 \%$ CI $[-.064, .330])$. Estimation for measures based on behavior towards the group should not be interpreted because of the small number of the effect sizes and studies. 


\section{Location}

There were no significant differences in mean effect sizes between studies conducted in the USA and in other locations $(b=-.171,95 \%$ CI $[-.491, .150], p=$ $.283)$.

Sample type

Sample type was a significant moderator $(b=.361,95 \%$ CI $[.105, .616], p=$ .007). Specifically, studies with students as participants demonstrated higher correlations between entitativity of the group and prejudice toward the group (ES = $.591,95 \%$ CI $[.399, .783])$ compared to participants recruited from the general population $(\mathrm{ES}=.230,95 \% \mathrm{CI}[.045, .415])$.

\section{Study design}

Study design was also a significant moderator $(b=-.368,95 \%$ CI $[-.659,-.077]$, $p=.017)$. Specifically, in experimental studies correlation between entitativity of the group and prejudice toward the group $(\mathrm{ES}=.141,95 \%$ CI $[-.108, .391])$ was lower compared to cross-sectional studies $(\mathrm{ES}=.516,95 \%$ CI $[.354, .677])$. 
Table 2. Moderator analysis results

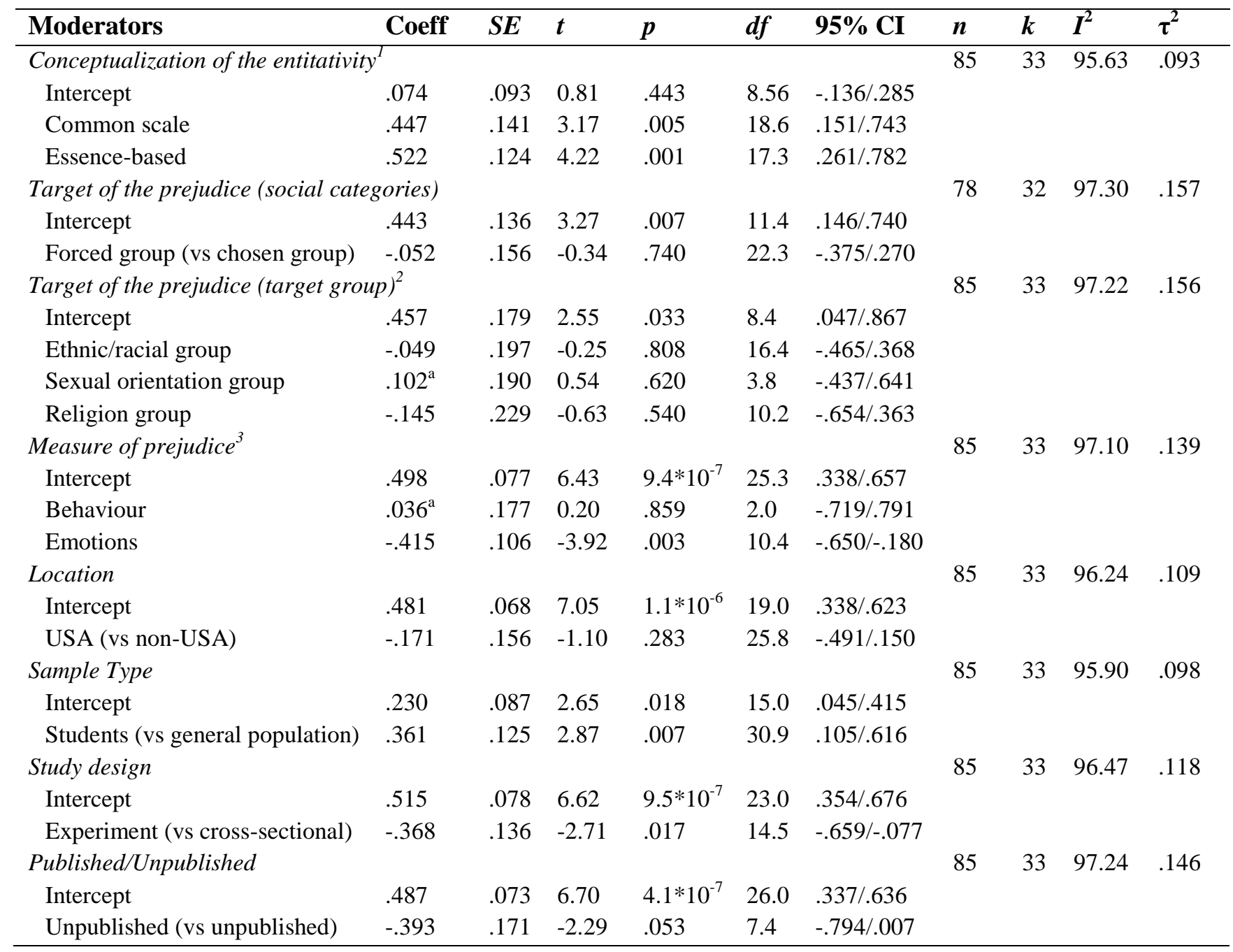

Note. $n$ - number of effect sizes; $k$ - number of independent samples; $d f$ - Satterthwaite degrees of freedom; $I^{2}$ - ratio of true heterogeneity to total variance across the observed effect sizes; $\tau^{2}-$ between-study variance in study-average effect sizes. Only values of target of the prejudice with the Satterthwaite degrees of freedom higher than 4 may be interpreted (if the Satterthwaite degrees of freedom are less than 4 , the probability of a Type I error is much higher than 0.05 and one should not trust the results).

${ }^{1}$ - Agency-based entitativity approach is reference category.

${ }^{2}$ - Other group is reference category.

${ }^{3}$ - Attitudes towards the group is reference category.

a - Satterthwaite degrees of freedom $<4$, one should not trust the results. 
Table 3. Effect sizes by moderators

\begin{tabular}{|c|c|c|c|c|c|c|c|c|c|c|}
\hline Moderators & $n$ & $\boldsymbol{k}$ & Fisher's $z$ & $S E$ & $t$ & $p$ & $d f$ & $95 \% \mathrm{CI}$ & $I^{2}$ & $\tau^{2}$ \\
\hline \multicolumn{11}{|c|}{ Conceptualization of the entitativity } \\
\hline Agency-based & 14 & 10 & .121 & .110 & 1.10 & .299 & 9.0 & $-.128 / .370$ & 97.92 & .110 \\
\hline Common scale & 43 & 16 & .537 & .098 & 5.46 & $6.6 * 10^{-5}$ & 15.0 & $.328 / .747$ & 95.38 & .125 \\
\hline Essence-based & 28 & 10 & .601 & .077 & 7.77 & $2.8^{*} 10^{-5}$ & 9.0 & $.426 / .776$ & 92.05 & .071 \\
\hline \multicolumn{11}{|c|}{ Target of the prejudice (social categories) } \\
\hline Chosen group & 23 & 13 & .410 & .127 & 3.23 & .007 & 12.0 & $.133 / .687$ & 96.96 & .133 \\
\hline Forced group & 55 & 23 & .365 & .080 & 4.56 & $1.5^{*} 10^{-4}$ & 22.0 & $.199 / .530$ & 97.39 & .161 \\
\hline \multicolumn{11}{|c|}{ Target of the prejudice (target group) } \\
\hline Ethnic/racial group & 45 & 20 & .386 & .086 & 4.51 & $2.4 * 10^{-4}$ & 19.0 & $.207 / .565$ & 97.63 & .164 \\
\hline Sexual orientation group & 7 & 5 & .499 & .085 & 5.88 & .004 & 4.0 & $.262 / .735$ & 91.73 & .051 \\
\hline Religion group & 13 & 6 & .296 & .129 & 2.30 & .070 & 5.0 & $-.035 / .627$ & 97.09 & .108 \\
\hline Other groups & 20 & 10 & .438 & .168 & 2.60 & .029 & 9.0 & $.057 / .818$ & 96.78 & .200 \\
\hline \multicolumn{11}{|l|}{ Measure of prejudice } \\
\hline Attitudes & 70 & 27 & .477 & .079 & 6.03 & $2.3 * 10^{-6}$ & 26.0 & $.315 / .640$ & 97.60 & .164 \\
\hline Behavior & 3 & 3 & $.590^{\mathrm{a}}$ & .127 & 4.65 & .044 & 2.0 & $.040 / 1.14$ & 87.66 & .034 \\
\hline Emotions & 12 & 9 & .133 & .085 & 1.56 & .159 & 8.0 & $-.064 / .330$ & 91.85 & .052 \\
\hline \multicolumn{11}{|l|}{ Location } \\
\hline USA & 21 & 13 & .311 & .140 & 2.21 & .047 & 12.0 & $.005 / .616$ & 97.20 & .114 \\
\hline Non-USA & 64 & 20 & .481 & .068 & 7.05 & $1.1 * 10^{-6}$ & 19.0 & $.338 / .623$ & 95.20 & .103 \\
\hline \multicolumn{11}{|l|}{ Sample Type } \\
\hline General population & 39 & 16 & .230 & .087 & 2.65 & .018 & 15.0 & $.045 / .415$ & 96.90 & .096 \\
\hline Students & 46 & 17 & .591 & .091 & 6.53 & $7.1 * 10^{-6}$ & 16.0 & $.399 / .783$ & 94.14 & .102 \\
\hline \multicolumn{11}{|l|}{ Study design } \\
\hline Cross-sectional & 71 & 24 & .516 & .078 & 6.60 & $9.8 * 10^{-7}$ & 23.0 & $.354 / .677$ & 96.92 & .150 \\
\hline Experiment & 14 & 9 & .141 & .108 & 1.31 & .228 & 8.0 & $-.108 / .391$ & 93.94 & .052 \\
\hline \multicolumn{11}{|l|}{ Published/Unpublished } \\
\hline Published & 69 & 27 & .487 & .073 & 6.7 & $4.1 * 10^{-7}$ & 26.0 & $.337 / .636$ & 97.24 & .145 \\
\hline Unpublished & 16 & 6 & .093 & .155 & 0.60 & .574 & 5.0 & $-.306 / .493$ & 97.24 & .151 \\
\hline
\end{tabular}

Note. $n$-number of effect sizes; $k$ - number of independent samples; $d f$-Satterthwaite degrees of

freedom (if the Satterthwaite degrees of freedom are less than 4, the probability of a Type I error is much higher than 0.05 and one should not trust the results); $I^{2}$ - ratio of true heterogeneity to total variance across the observed effect sizes; $\tau^{2}$ - between-study variance in study-average effect sizes.

a - Satterthwaite degrees of freedom $<4$, one should not trust the results. 

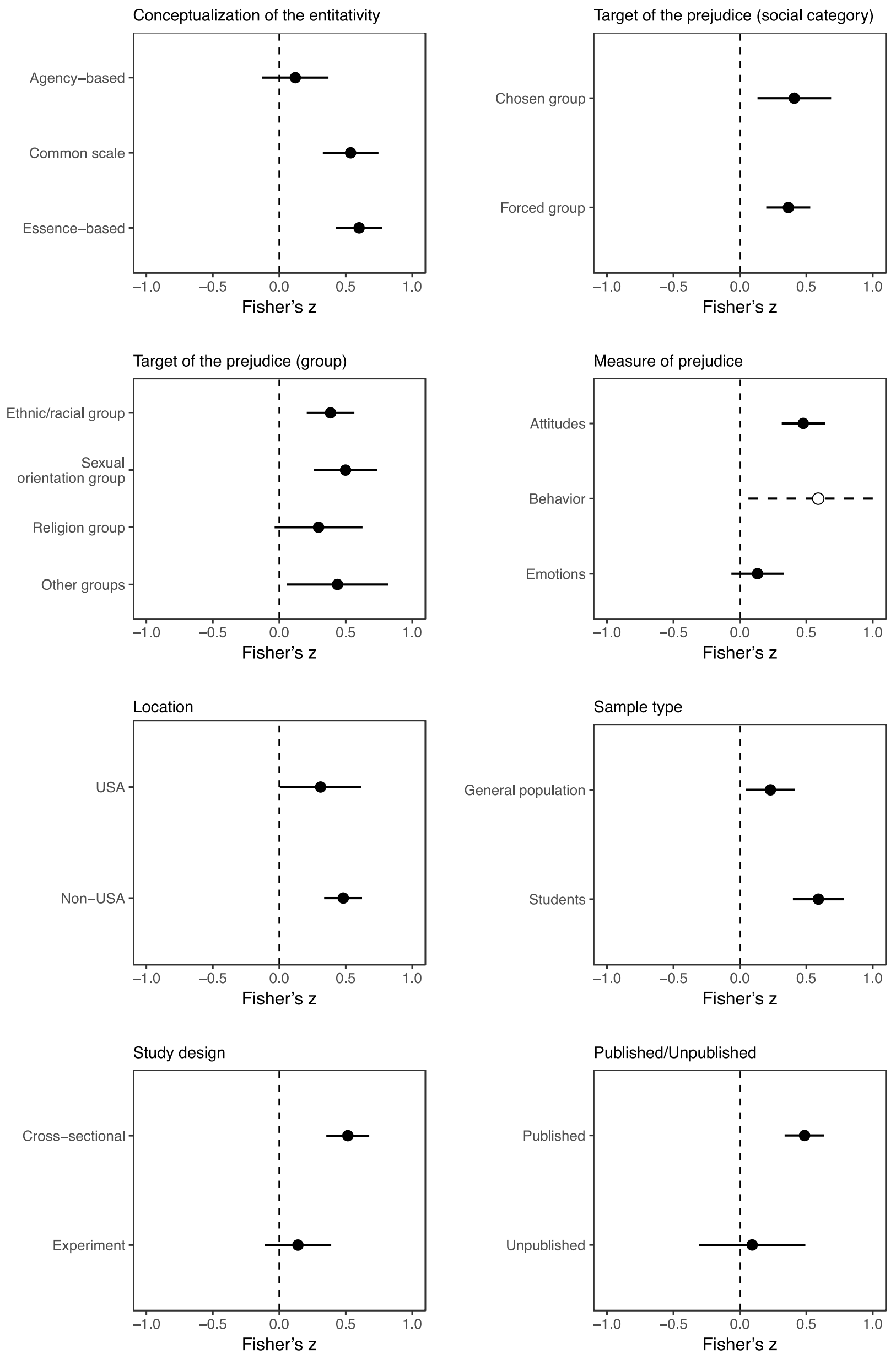
Figure 2. Mean effect sizes by moderators. Whiskers represent $95 \%$ confidence intervals. Empty points and dashed whiskers were used for estimations, which one should not trust (because of small number of effect sizes).

\section{Publication bias analysis}

Results of both the PET and PEESE models with RVE indicated no evidence of publication bias $\left(\mathrm{PET}_{\mathrm{RVE}} b_{1}=4.98, p=.071 ; \mathrm{PEESE}_{\mathrm{RVE}} b_{1}=27.94, p=.101\right)$. Metaregression also showed there were no significant differences in mean effect sizes between published and unpublished studies (see Tables 2 and 3 and Figure $2 \mathrm{~h}$ ).

Several publication bias tests based on aggregated data were also conducted. A visual inspection of the funnel plot (Figure 3, left panel) showed no strong evidence for asymmetry. Egger's regression test for funnel plot asymmetry was significant $(z=$ $2.46, p=.014)$. However, the rank correlation test was not significant (tau $=0.16, p=$ .211). The trim-and-fill method showed there were zero missing studies on the left side of the funnel plot. Thus, there was no strong and robust evidence of funnel plot asymmetry. An inspection of the contour-enhanced funnel plot did not reveal an over-representation of effect sizes in the significance contours (Figures 3, right panel), indicating a low risk of publication bias. Thus, the analysis did not identify any asymmetry or over-representation effect sizes with $p$-values just below the conventional cutoff value .05 . Results of the PET model showed a significant effect (PET $b_{1}=8.47, p=.004$ ). According to the two-step conditional PET-PEESE procedure, in this case one should use a PEESE estimate, which was also significant (PEESE $b_{1}=53.36, p=.012$ ). Thus PET-PEESE indicated evidence of publication 
bias among studies. Results of weight-function modeling indicated that the model adjusted for publication bias does not increase model fit $\left(\chi^{2}(1)=2.81, p=.093\right)$, providing no evidence of publication bias.

To summarize, the majority of the methods indicated no evidence of publication bias. Given the dependencies in analyzed data, it can be assumed that publication bias analysis methods based on RVE are more appropriate for the present analysis. These methods did not identify publication bias. Thus, we summarize that there is no strong and robust evidence of publication bias.
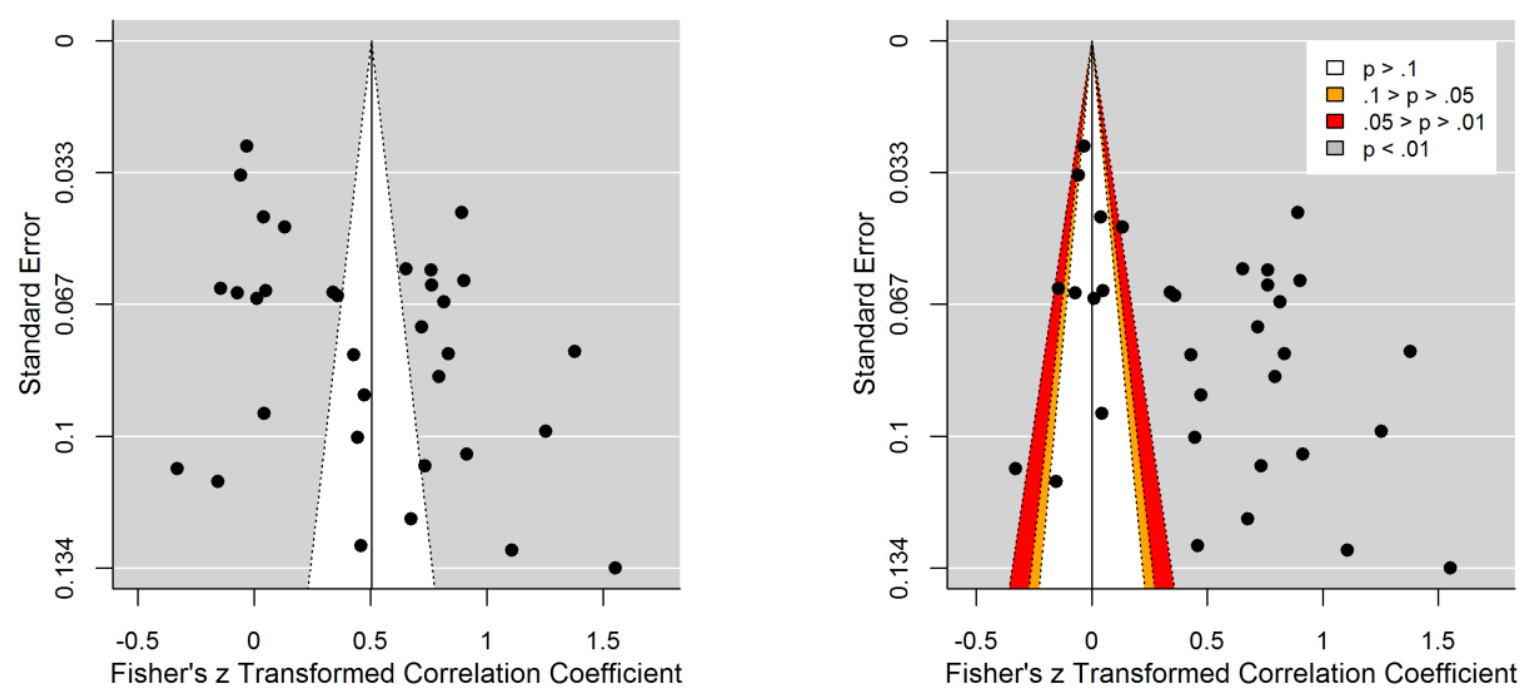

Figure 3. Funnel plot (left panel) and contour-enhanced funnel plot (right panel). 


\section{Discussion}

This meta-analysis is the first to quantitatively summarize the research on the relationship between entitativity and prejudice. The results obtained demonstrate three important conclusions.

First, our findings show that out-group entitativity is positively associated with prejudice (Fisher's $z=.414,95 \%$ CI $[.272, .557], p<.0001$ ); that is, people are more prejudiced toward groups that are perceived as coherent. This result highlights the significant role of out-group entitativity in the analysis of prejudice. Because groups can differ in their entitativity, it may be one of the central factors (no less important than relatively stable personality dispositions and social identification) in explaining the differences in the manifestation of prejudices.

Second, we found that the relationship between entitativity and prejudice is moderated by some characteristics of the studies. In particular, we identified that the correlation depends on how entitativity was conceptualized . It seems that an agencybased approach to entitativity conceptualization differs from essence-based and common scale approaches, at least in terms of the relationship between entitativity and prejudice. This result is not surprising, because only social categories were included in this analysis. Lickel et al. (2000) defined social categories as 'groups that exist because they identify a certain class of individuals who are perceived to share certain characteristics' (p. 225). The previous works confirmed that social categories are more often perceived as homogeneous in common attributes (traits and traitrelated behavior) and less often as interacting individuals with a common goal (Lickel et al., 2000; Spencer-Rodgers, Hamilton, et al., 2007). In other words, 
entitativity of the social categories measures higher on essence-based scales and lower on agency-based scales. Our results provide additional evidence of this thesis, because we did not reveal a relationship between agency-based entitativity and prejudice, while the essence-based entitativity was associated with prejudice towards different social categories. This is probably because each approach actualized only certain group properties. Therefore, social categories are such large groups that it is difficult to imagine that all members of these groups may have some common goal (for example, to harm another group) and interact with each other to achieve this goal. As a result, in terms of the agency-based approach social categories could be perceived as being less dangerous, which could lead to a lack of association with prejudice. At the same time, the essence-based approach emphasizes the similarity of group members and increases the likelihood of stereotype formation that can contribute to the attribution of negative characteristics and intentions, which in turn increases the level of prejudice towards the out-group.

The next moderator that we tested was the target of prejudice. The analysis demonstrated that there were no differences in the relationship between entitativity and prejudice depending on the target of the group and in case of chosen or forced social categories. It seems that entitativity is associated with prejudice, regardless of the type of social category that was the target of prejudice. The best confirmation of this conclusion is the positive correlation between the entitativity of the sexual orientation group and prejudice that was obtained in our meta-analysis. Homosexuals could not definitively be considered as a chosen or a forced social category; some believes that sexual orientation is an innate characteristic (forced social category), 
others that homosexuals 'chose this way' (chosen social category), but those and others can demonstrate prejudice towards homosexuals.

For the next moderator, we considered the measure of prejudice. We found the highest correlation was observed when prejudice was measured as attitudes toward the out-group (including explicit attitudes, stereotypes and social distancing), and zero correlation was observed when prejudice was measured as emotions toward the out-group. This is an interesting result that points to entitativity as a cognitive phenomenon (Hamilton et al., 2002). Entitativity as a result of group perception is strongly associated with traits and intention attribution and stereotyping (Crawford et al., 2002; Spencer-Rodgers, Hamilton, et al., 2007; V. Y. Yzerbyt, Rogier, \& Fiske, 1998). As a result, the measures of prejudice that predominantly included the cognitive component of attitudes demonstrated the link with entitativity. Meanwhile, emotions are more often related to the perception of intergroup relations than to the perception of group properties (Stenstrom et al., 2008), and this could lead to the link between emotions and entitativity, though this link was not significant.

We also showed that the additional moderators (study characteristics) moderated the relationship between entitativity and prejudice. Students demonstrate higher correlations between entitativity of the group and prejudice toward the group than did the general population. These differences are not unusual. Previous meta-analysis found that effect sizes obtained from student samples frequently differed from effect sizes obtained from non-student samples, both directionally and in magnitude (Peterson, 2001). In particular, student samples are more homogeneous within the main demographic characteristics than general population samples, leading to more 
homogeneous responses from students and to a more obvious confirmation of the effects studied.

The entitativity of social categories does not differ between studies conducted in USA and in other locations. Kashima et al. (2005) demonstrated that entitativity of the intimacy group (family, friends) differs across three East Asian cultures (Japan, Korea, and Hong Kong), three English-speaking cultures (Australia, the UK, and the USA), and two continental European cultures (Francophone Belgium and Germany). Nonetheless, it seems that there are no such differences in relation to social categories. Probably the representation of family (who could be considered as a family member, and why) is more culturally specific, while beliefs that all people belong to different social categories are more universal.

Finally, we demonstrated that in the experimental studies, out-group entitativity is less associated with prejudice compared to the results from cross-sectional studies. Out of fourteen effect sizes in this analysis, ten were similar to results obtained in similar studies (Effron, 2015; Effron \& Knowles, 2015a; Effron \& Knowles, 2015b). In each case, the results can be related to the specifics of the experimental procedure in which most effects were obtained. More detailed analysis of these findings requires more data from different studies.

The confirmation that study characteristics affect the expected effect sizes has important practical implications for planning and implementing future research.

Third, the analysis showed a huge heterogeneity in the magnitude of observed effect sizes between studies within subgroups identified by analyzed moderator variables $\left(I^{2}\right.$ is about 90\%). Even though the effects of some moderators were 
identified, they do not explain the variance of observed effect sizes across studies. A huge level of heterogeneity could be explained by the enormous diversity of characteristics in entitativity and prejudice studies. Measurement of entitativity varies from study to study and typically has been constructed for each study, based only partially or not at all on previous work. It means that even the scales classified to one approach (e.g. the essence-based entitativity approach) are different from each other. This fact is not critical for understanding group entitativity. Kashima with colleagues (2005) claimed 'entitativity is not a coherent unitary psychological phenomenon, but a collection of diverse attributes of the psychological meaningfulness of a social entity' (p. 162). Groups can attain their entitativity in different ways, for example through the actualization of different aspects of similarity. As a result, the differences between scales in one approach cannot lead to a strong difference in perceived entitativity, but can contribute to the heterogeneity of the results obtained. The same is true of measuring prejudice.

The results of this meta-analysis contribute to the current literature on entitativity and prejudice in examining moderators that may influence this relationship. However, this analysis has limitations. First, the results of meta-analysis were limited by the availability of research for inclusion. Moreover, the majority of the effect sizes were taken from studies conducted in three countries (the United States, Belgium, and Russia) and focused predominantly toward ethnic groups. Future meta-analyses may be in a better position when the new studies will be conducted. 
Second, because of the small number of effect sizes, we focused on only three moderators that cannot account for all the unexplained variances. Other potential moderators may help more detail explain the relationship between entitativity and prejudice. So, despite the fact that relationships between White and Black or between German and Turkish were categorized as relationships between ethnic/racial groups, the social and historical contexts of these relations are very different and can affect the relationship between entitativity and prejudice. Finally, this meta-analysis focused on the correlations between entitativity and prejudice, but these variables could be mediated by many another variables. In general, it can be assumed that the relationship between entitativity and prejudice is more complex, since both these constructs are associated with identification. So, Stenstrom et al. (2008) demonstrated that in the case of out-group, the relations between identification and negative attitudes was mediated through perceptions of group entitativity. The study of such an indirect link may be the subject of future research. Despite these limitations, the present meta-analysis provides empirical support for the importance role of group entitativity in the intergroup relations.

\section{References}

*Agadullina, E. R. (2015). Entitativity and gender prejudice. Unpublished data.

*Agadullina, E. R. (2016). Essentialist beliefs about social categories in Russia. Unpublished data.

*Agadullina, E. R., \& Lovakov, A. V. (2017). Understanding entitativity: are there real differences between approaches? Psychology. Journal of Higher School of 
Economics, 14(3), 536-554.

*Andreychik, M. R., \& Gill, M. J. (2015). Do natural kind beliefs about social groups contribute to prejudice? Distinguishing bio-somatic essentialism from biobehavioral essentialism, and both of these from entitativity. Group Processes \& Intergroup Relations, 18(4), 454-474. http://doi.org/10.1177/1368430214550341

Askevis-Leherpeux, F. (2005). For and against: perceived entitativity of supportive and oppositional opinion groups. Group Processes \& Intergroup Relations, 8(1), 27-37. http://doi.org/10.1177/1368430205048617

Bangerter, A. (2005). Entitativity of Generations, Age Groups and Cohorts as Perceived by Young Adults. Swiss Journal of Psychology, 64(4), 273-280. http://doi.org/10.1024/1421-0185.64.4.273

Baumeister, R. F., \& Vohs, K. D. (Eds.). (2007). Encyclopedia of Social psychology. SAGE Publications.

Boldry, J. G., Gaertner, L., \& Quinn, J. (2007). Measuring the Measures: A MetaAnalytic Investigation of the Measures of Outgroup Homogeneity. Group Processes \& Intergroup Relations, 10(2), 157-178. http://doi.org/10.1177/1368430207075153

Borenstein, M., Hedges, L. V., Higgins, J. P. T., \& Rothstein, H. R. (2009). Introduction to Meta-Analysis. Chichester, UK: John Wiley \& Sons, Ltd. http://doi.org/10.1002/9780470743386

Brewer, M. B., Hong, Y., \& Li, Q. (2004). Dynamic Entitivity: Perceiving Groups as Actors. In V. Y. Yzerbyt, C. Judd, \& O. Corneille (Eds.), The psychology of group perception: Perceived variability, entitativity, and essentialism (pp. 25- 
38). New York, NY, US: Psychology Press.

Brickman, D. W. (2009). The Implications of Essentialist Beliefs for Prejudice. The University of Michigan.

Brigham, J. C. (1993). College students' racial attitudes. Journal of Applied Social Psychology, 23(23), 1933-1967. http://doi.org/10.1111/j.15591816.1993.tb01074.x

Brown, R. (2000). Social identity theory: Past achievements, current problems and future challenges. European Journal of Social Psychology, 30, 745-778. http://doi.org/10.1002/1099-0992(200011/12)30:6<745::AID-EJSP24>3.0.CO;2$\mathrm{O}$

Campbell, D. T. (1958). Common fate, similarity, and other indices of the status of aggregates of persons as social entities. Behavioral Science, 3(1), 14-25.

Castano, E., Yzerbyt, V. Y., \& Bourguignon, D. (2003). We are one and I like it: The impact of ingroup entitativity on ingroup identification. European Journal of Social Psychology, 33(6), 735-754. http://doi.org/10.1002/ejsp.175

Crawford, M. T., Sherman, S. J., \& Hamilton, D. L. (2002). Perceived entitativity, stereotype formation, and the interchangeability of group members. Journal of Personality and Social Psychology, 83(5), 1076-1094.

http://doi.org/10.1037/0022-3514.83.5.1076

Crump, S. A., Hamilton, D. L., Sherman, S. J., Lickel, B., \& Thakkar, V. (2010). Group entitativity and similarity: Their differing patterns in perceptions of groups. European Journal of Social Psychology, 40(7), 1212-1230. http://doi.org/10.1002/ejsp.716 
Dasgupta, N., Banaji, M. R., \& Abelson, R. P. (1999). Group entitativity and group perception: Associations between physical features and psychological judgment. Journal of Personality and Social Psychology, 77(5), 991-1003. http://doi.org/10.1037/0022-3514.77.5.991

Del Re, A. C. (2013). compute.es: Compute Effect Sizes. R package version 0.2-2.

Del Re, A. C., \& Hoyt, W. T. (2012). MAc: Meta-Analysis with Correlations. R package version 1.1 .

Demoulin, S., Leyens, J., \& Yzerbyt, V. Y. (2006). Lay theories of essentialism. Group Processes \& Intergroup Relations, 9(1), 25-42. http://doi.org/10.1177/1368430206059856

Denson, T. F., Lickel, B., Curtis, M., Stenstrom, D. M., \& Ames, D. R. (2006). The roles of entitativity and essentiality in judgments of collective responsibility. Group Processes \& Intergroup Relations, 9(1), 43-61. http://doi.org/10.1177/1368430206059857

Duval, S., \& Tweedie, R. (2000). Trim and Fill: A Simple Funnel-Plot-Based Method of Testing and Adjusting for Publication Bias in Meta-Analysis. Biometrics, 56(2), 455-463. http://doi.org/10.1111/j.0006-341X.2000.00455.x

*Effron, D. (2015). Entitativity, responsibility, and the acceptability of prejudice. Unpublished manuscript.

*Effron, D., \& Knowles, E. D. (2015a). Entitativity and intergroup bias: How belonging to a cohesive group allows people to express their prejudices. Journal of Personality and Social Psychology, 108(2), 234-253. http://doi.org/10.1037/pspa0000020.supp 
*Effron, D., \& Knowles, E. D. (2015b). Entitativity and the acceptability of prejudice. Unpublished manuscript.

Fisher, Z., \& Tipton, E. (2015). robumeta: An R-package for robust variance estimation in meta-analysis (arXiv preprint, arXiv:1503.02220).

Futaki, N., Watanabe, T., Sakurai, R., \& Karasawa, K. (2016). The effects of entitativity on behavioral intentions toward an ambivalent group: From the perspective of ageism. Japanese Journal of Social Psychology, 32(2), 81-91.

Gaertner, L., \& Schopler, J. (1998). Perceived ingroup entitativity and intergroup bias: an interconnection of self and others. European Journal of Social Psychology, 28(6), 963-980. http://doi.org/10.1002/(SICI)10990992(1998110)28:6<963::AID-EJSP905>3.0.CO;2-S

Grzesiak-Feldman, M., \& Suszek, H. (2008). Conspiracy Stereotyping and Perceptions of Group Entitativity of Jews, Germans, Arabs and Homosexuals by Polish Students. Psychological Reports, 102(3), 755-758.

http://doi.org/10.2466/pr0.102.3.755-758

*Gulevich, O. A., Osin, E. N., Isaenko, N. A., \& Brainis, L. M. (2016). Attitudes To Homosexuals in Russia: Content, Structure, and Predictors. Psychology. Journal of the Higher School of Economics., 13(1), 79-110.

Hamilton, D. L., Sherman, S. J., \& Castelli, L. (2002). A Group By Any Other Name-The Role of Entitativity in Group Perception. In W. Stroebe \& M. Hewstone (Eds.), European Review of Social Psychology (Vol. 12, pp. 139-166). Chichester: Wiley. http://doi.org/10.1080/14792772143000049 *Haqanee, Z., Lou, E., \& Lalonde, R. N. (2014). Natural kind and entitative beliefs in 
relation to prejudice toward mental disorders. Journal of Applied Social Psychology, 44(2), 145-153. http://doi.org/10.1111/jasp.12249

Haslam, N. (2003). Folk psychiatry: Lay thinking about mental disorder. Social Research: An International Quarterly, 70(2), 621-644. Retrieved from http://socialresearch.metapress.com/index/5DJHV2JFU5299BQ6.pdf

Haslam, N., \& Levy, S. R. (2006). Essentialist beliefs about homosexuality: structure and implications for prejudice. Personality and Social Psychology Bulletin, 32(4), 471-485. http://doi.org/10.1177/0146167205276516

Haslam, N., Rothschild, L., \& Ernst, D. (2000). Essentialist beliefs about social categories. British Journal of Social Psychology, 39(1), 113-127. http://doi.org/10.1348/014466600164363

*Haslam, N., Rothschild, L., \& Ernst, D. (2002). Are essentialist beliefs associated with prejudice? British Journal of Social Psychology, 41, 87-100. http://doi.org/10.1348/014466602165072

Hedges, L. V., Tipton, E., \& Johnson, M. C. (2010). Robust variance estimation in meta-regression with dependent effect size estimates. Research Synthesis Methods, 1(1), 39-65. http://doi.org/10.1002/jrsm.5

Herek, G. M. (1984). Beyond "Homophobia": A Social Psychological Perspective on Attitudes Toward Lesbians and Gay Men. Journal of Homosexuality, 10(1-2), 121. http://doi.org/10.1300/J082v10n01

*Hodson, G., \& Skorska, M. N. (2015). Tapping generalized essentialism to predict outgroup prejudices. British Journal of Social Psychology, 54(2), 371-382. http://doi.org/10.1111/bjso.12083 
Horvath, M., \& Ryan, A. M. (2003). Antecedents and potential moderators of the relationship between attitudes and hiring discrimination on the basis of sexual orientation. Sex Roles, 48(3-4), 115-130.

http://doi.org/10.1023/A:1022499121222

Hughey, M. (2010). The (dis)similarities of white racial identities: the conceptual framework of "hegemonic whiteness." Ethnic and Racial Studies, 33(8), 12891309. http://doi.org/10.1080/01419870903125069

Hunter, J. E., \& Schmidt, F. L. (2004). Methods of meta-analysis (2nd ed.). Thousand Oaks, CA: Sage.

Judd, C. M., Park, B., Yzerbyt, V. Y., Gordijn, E. H., \& Muller, D. (2005). Attributions of intergroup bias and outgroup homogeneity to ingroup and outgroup others. European Journal of Social Psychology, 35(6), 677-704. http://doi.org/10.1002/ejsp.281

Kashima, Y., Kashima, E., Chiu, C.-Y., Farsides, T., Gelfand, M., Hong, Y.-Y., ... Yzerbyt, V. Y. (2005). Culture, essentialism, and agency: are individuals universally believed to be more real entities than groups? European Journal of Social Psychology, 35(2), 147-169. http://doi.org/10.1002/ejsp.237

*Keller, J. (2005). In genes we trust: the biological component of psychological essentialism and its relationship to mechanisms of motivated social cognition. Journal of Personality and Social Psychology, 88(4), 686-702. http://doi.org/10.1037/0022-3514.88.4.686

Lee, S. a., Reid, C. a., Short, S. D., Gibbons, J. a., Yeh, R., \& Campbell, M. L. (2013). Fear of Muslims: Psychometric evaluation of the Islamophobia Scale. 
Psychology of Religion and Spirituality, 5(3), 157-171.

http://doi.org/10.1037/a0032117

Lenhard, W., \& Lenhard, A. (2016). Calculation of Effect Sizes.

http://doi.org/10.13140/RG.2.1.3478.4245

Levy, S. R., Plaks, J., Hong, Y.-Y., Chiu, C.-Y., \& Dweck, C. S. (2001). Static versus dynamic theories and the perception of groups: different routes to different destinations. Personality and Social Psychology Review, 5(2), 156-168. http://doi.org/10.1207/S15327957PSPR0502

Lickel, B., Hamilton, D. L., Wieczorkowska, G., Lewis, A., Sherman, S. J., \& Uhles, A. N. (2000). Varieties of groups and the perception of group entitativity. Journal of Personality and Social Psychology, 78(2), 223-246. http://doi.org/10.1037/0022-3514.78.2.223

Lickel, B., Schmader, T., \& Hamilton, D. L. (2003). A case of collective responsibility: who else was to blame for the Columbine high school shootings? Personality and Social Psychology Bulletin, 29(2), 194-204. http://doi.org/10.1177/0146167202239045

Miles, E., \& Crisp, R. J. (2013). A meta-analytic test of the imagined contact hypothesis. Group Processes \& Intergroup Relations, 17(1), 3-26. http://doi.org/10.1177/1368430213510573

Newheiser, A.-K. (2012). Justice is not equal for all groups: Punishment, Retaliation, and Justification of Prejudice Toward Cohesive groups. Yale University.

*Newheiser, A.-K., \& Dovidio, J. F. (2012). Individual differences and intergroup 
bias: Divergent dynamics associated with prejudice and stereotyping. Personality and Individual Differences, 53(1), 70-74.

http://doi.org/10.1016/j.paid.2012.02.024

Newheiser, A.-K., \& Dovidio, J. F. (2015). High outgroup entitativity can inhibit intergroup retribution. British Journal of Social Psychology, 54(2), 341-358. http://doi.org/10.1111/bjso.12078

Newheiser, A.-K., Sawaoka, T., \& Dovidio, J. F. (2012). Why do we punish groups? High entitativity promotes moral suspicion. Journal of Experimental Social Psychology, 48(4), 931-936. http://doi.org/10.1016/j.jesp.2012.02.013

*Newheiser, A.-K., Tausch, N., Dovidio, J. F., \& Hewstone, M. (2009). Entitativity and prejudice: Examining their relationship and the moderating effect of attitude certainty. Journal of Experimental Social Psychology, 45(4), 920-926. http://doi.org/10.1016/j.jesp.2009.04.024

*Ommundsen, R., Yakushko, O., Veer, K. Van Der, \& Ulleberg, P. (2013). Exploring the relationships between fear-related xenophobia, perceptions of out-group entitativity, and social contact in Norway. Psychological Reports: Sociocultural Issues in Psychology, 112(1), 109-124.

http://doi.org/10.2466/17.07.21.PR0.112.1.109-124

Onraet, E., Van Hiel, A., Dhont, K., Hodson, G., Schittekatte, M., \& De Pauw, S. (2015). The Association of Cognitive Ability with Right-wing Ideological Attitudes and Prejudice: A Meta-analytic Review. European Journal of Personality, 29(6), 599-621. http://doi.org/10.1002/per.2027

Pereira, M. E., Alvaro, J.-L., \& Garrido, A. (2016). Essentialization processes in men 
and women: A Brazil-Spain comparative study. Anales de Psicología, 32(1), $190-198$.

Pereira, M. E., Álvaro, J. L., Oliveira, A. C., \& Dantas, G. S. (2011). Stereotypes and the essencialization of black and white people: A comparative study | [Estereótipos e essencialização de brancos e negros: um estudo comparativo]. Psicologia E Sociedade, 23(1), 144-153.

Peterson, R. A. (2001). On the Use of College Students in Social Science Research: Insights from a Second-Order Meta-analysis. Journal of Consumer Research, 28(3), 450-461. http://doi.org/10.1086/323732

Peterson, R. A., \& Brown, S. P. (2005). On the Use of Beta Coefficients in MetaAnalysis. Journal of Applied Psychology, 90(1), 175-181. http://doi.org/10.1037/0021-9010.90.1.175

Pettigrew, T. F., \& Meertens, R. W. (1995). Subtle and blatant prejudice in Western Europe. European Journal of Social Psychology, 57, 57-75.

*Phelps, J. M., Ommundsen, R., Türken, S., \& Ulleberg, P. (2013). Intergroup Perception and Proactive Majority Integration Attitudes. Social Psychology, 44(3), 196-207. http://doi.org/10.1027/1864-9335/a000104

Plaks, J. E., Levy, S. R., Dweck, C. S., \& Stroessner, S. J. (2004). In the eye of the beholder: Lay theories and the perception of group entitativity, variability, and essence. In V. Yzerbyt, C. M. Judd, \& O. Corneille (Eds.), The psychology of group perception: Perceived variability, entitativity, and essentialism (pp. 127146). New York: Psychology Press.

Prentice, D. A., \& Miller, D. T. (2007). Psychological essentialism of human 
categories. Current Directions in Psychological Science, 16(4), 202-206.

http://doi.org/10.1111/j.1467-8721.2007.00504.x

Pustejovsky, J. (2017). clubSandwich: Cluster Robust (Sandwich) Variance

Estimators with Small-Sample Corrections. R package version 0.2.3.

Ramirez, L., Uruena, H., \& Moreno, P. (2012). Essentialist discourse about race in

Colombia and social implications. Revista Latinoamericana de Psicología, 44(3), $119-131$.

*Roets, A. (2015). Unpublished data.

*Roets, A., \& Van Hiel, A. (2011). The role of need for closure in essentialist entitativity beliefs and prejudice: an epistemic needs approach to racial categorization. The British Journal of Social Psychology, 50, 52-73. http://doi.org/10.1348/014466610X491567

Rüsch, N., Corrigan, P. W., Wassel, A., Michaels, P., Olschewski, M., Wilkniss, S., \& Batia, K. (2009). Ingroup perception and responses to stigma among persons with mental illness. Acta Psychiatrica Scandinavica, 120(4), 320-328. http://doi.org/10.1111/j.1600-0447.2009.01403.x

*Rydell, R. J., Hugenberg, K., Ray, D., \& Mackie, D. M. (2007). Implicit theories about groups and stereotyping: The role of group entitativity. Personality and Social Psychology Bulletin, 33(4), 549-558.

http://doi.org/10.1177/0146167206296956

Sacchi, S., Castano, E., \& Brauer, M. (2009). Perceiving one's nation: Entitativity, agency and security in the international arena. International Journal of Psychology, 44(5), 321-332. http://doi.org/10.1080/00207590802236233 
Sáez, M. L. (1993). Typicity of gender identity and intergroup comparison. Revista de Psicología Social, 8(2), 189-200.

Sherman, S. J., \& Percy, E. J. (2010). The psychology of collective responsibility: When and why collective entities are likely to be held responsible for the misdeeds of individual members. Journal of Law \& Policy, 19, 137-170.

Sibley, C. G., \& Duckitt, J. (2008). Personality and prejudice: a meta-analysis and theoretical review. Personality and Social Psychology Review, 12(1954), 248279. http://doi.org/10.1177/1088868308319226

Simon, B., Mlicki, P., Johnston, L., Caetano, A., Warowicki, M., Van Knippenberg, A., \& Deridder, R. (1990). The effects of ingroup and outgroup homogeneity on ingroup favouritism, stereotyping and overestimation of relative ingroup size. European Journal of Social Psychology, 20(6), 519-523. http://doi.org/10.1002/ejsp.2420200606

Smith, S. J., Axelton, A. M., \& Saucier, D. A. (2009). The effects of contact on sexual prejudice: A meta-analysis. Sex Roles, 61(3-4), 178-191. http://doi.org/10.1007/s11199-009-9627-3

*Spencer-Rodgers, J., Hamilton, D. L., \& Sherman, S. J. (2007). The central role of entitativity in stereotypes of social categories and task groups. Journal of Personality and Social Psychology, 92(3), 369-388. http://doi.org/10.1037/00223514.92.3.369

Spencer-Rodgers, J., Williams, M. J., Hamilton, D. L., Peng, K., \& Wang, L. (2007). Culture and group perception: dispositional and stereotypic inferences about novel and national groups. Journal of Personality and Social Psychology, 93(4), 
525-543. http://doi.org/10.1037/0022-3514.93.4.525

Stanley, T. D., \& Doucouliagos, H. (2014). Meta-regression approximations to reduce publication selection bias. Research Synthesis Methods, 5(1), 60-78. http://doi.org/10.1002/jrsm.1095

*Stenstrom, D. M., Lickel, B., Denson, T. F., \& Miller, N. (2008). The roles of ingroup identification and outgroup entitativity in intergroup retribution. Personality and Social Psychology Bulletin, 34(11), 1570-1582. http://doi.org/10.1177/0146167208322999

Tajfel, H., \& Turner, J. C. (1986). The social identity theory of intergroup behavior. In S. Worchel \& W. G. Austin (Eds.), The psychology of intergroup relations (pp. 7-24). Chicago: Nelson-Hall.

Tanaka, G., Inadomi, H., Kikuchi, Y., \& Ohta, Y. (2004). Evaluating stigma against mental disorder and related factors. Psychiatry and Clinical Neurosciences, 58(5), 558-566. http://doi.org/10.1111/j.1440-1819.2004.01300.x

van Rijswijk, W., Haslam, S. A., \& Ellemers, N. (2006). Who do we think we are? The effects of social context and social identification on in-group stereotyping. The British Journal of Social Psychology / the British Psychological Society, 45(Pt 1), 161-174. http://doi.org/10.1348/014466605X39475

Vevea, J. L., \& Hedges, L. V. (1995). A general linear model for estimating effect size in the presence of publication bias. Psychometrika, 60(3), 419-435. http://doi.org/10.1007/BF02294384

Viechtbauer, W. (2010). Conducting Meta-Analyses in R with the metafor Package. Journal of Statistical Software, 36(3). http://doi.org/10.18637/jss.v036.i03 
Yzerbyt, V. Y., Judd, C., \& Corneille, O. (Eds.). (2004). The psychology of group perception: Perceived variability, entitativity, and essentialism. New York: Psychology Press.

Yzerbyt, V. Y., Rogier, A., \& Fiske, S. T. (1998). Group entitativity and social attribution: On translating situational constraints into stereotypes. Personality and Social Psychology Bulletin, 24(10), 1089-1103. http://doi.org/10.1177/01461672982410006

*denotes studies included in the meta-analysis 


\section{Appendix}

Summary of studies and samples included in the meta-analysis

\begin{tabular}{|c|c|c|c|c|c|c|c|c|c|c|}
\hline Source & $\mathbf{N}$ & $\begin{array}{l}\text { Sample } \\
\text { type }\end{array}$ & Location & Design & Published & $\begin{array}{l}\text { Entitativity } \\
\text { conceptualization }\end{array}$ & $\begin{array}{l}\text { Measure } \\
\text { of } \\
\text { prejudice }\end{array}$ & $\begin{array}{l}\text { Target of } \\
\text { prejudice } \\
\text { (group) }\end{array}$ & $\begin{array}{l}\text { Target of } \\
\text { prejudice } \\
\text { (social } \\
\text { category) }\end{array}$ & Correlation \\
\hline \multirow[t]{4}{*}{ Agadullina \& Lovakov, 2017} & 193 & GP & Russia & C-S & Yes & CS & Attitudes & Ethnic/racial & Forced & .493 \\
\hline & & & & & & $\mathrm{CS}$ & Attitudes & Ethnic/racial & Forced & .160 \\
\hline & & & & & & CS & Emotions & Ethnic/racial & Forced & .453 \\
\hline & & & & & & $\mathrm{CS}$ & Behavior & Ethnic/racial & Forced & .519 \\
\hline \multirow[t]{2}{*}{ Agadullina, 2015} & 88 & GP & Russia & C-S & No & $\mathrm{CS}$ & Attitudes & Gender & Forced & -.300 \\
\hline & & & & & & CS & Emotions & Gender & Forced & -.171 \\
\hline \multirow[t]{10}{*}{ Agadullina, 2016} & $\begin{array}{l}298- \\
587\end{array}$ & GP & Russia & C-S & No & $\mathrm{CS}$ & Attitudes & Ethnic/racial & Forced & .399 \\
\hline & & & & & & $\mathrm{CS}$ & Attitudes & $\begin{array}{l}\text { Sexual } \\
\text { orientation }\end{array}$ & Homo & .188 \\
\hline & & & & & & $\mathrm{CS}$ & Emotions & $\begin{array}{l}\text { Sexual } \\
\text { orientation }\end{array}$ & Homo & .180 \\
\hline & & & & & & $\mathrm{CS}$ & Attitudes & Ethnic/racial & Forced & -.389 \\
\hline & & & & & & CS & Attitudes & Ethnic/racial & Forced & -.362 \\
\hline & & & & & & $\mathrm{CS}$ & Emotions & Ethnic/racial & Forced & .241 \\
\hline & & & & & & CS & Attitudes & Religion & Chosen & .149 \\
\hline & & & & & & $\mathrm{CS}$ & Attitudes & Religion & Chosen & .181 \\
\hline & & & & & & CS & Emotions & Religion & Chosen & .101 \\
\hline & & & & & & $\mathrm{CS}$ & Emotions & Religion & Chosen & .173 \\
\hline \multirow{2}{*}{$\begin{array}{l}\text { Andreychik \& Gill, } 2015 \\
\text { (Study 1) }\end{array}$} & 164 & Stud & USA & C-S & Yes & $\mathrm{EB}$ & Attitudes & Ethnic/racial & Forced & .570 \\
\hline & & & & & & $\mathrm{EB}$ & Attitudes & Ethnic/racial & Forced & .610 \\
\hline $\begin{array}{l}\text { Andreychik \& Gill, } 2015 \\
\text { (Study 3) }\end{array}$ & 242 & GP & USA & Exp & Yes & $\mathrm{EB}$ & Emotions & Other & Chosen & .322 \\
\hline $\begin{array}{l}\text { Effron \& Knowles, 2015a } \\
\text { (Study 1) }\end{array}$ & 248 & GP & USA & Exp & Yes & $\mathrm{AB}$ & Emotions & Ethnic/racial & Forced & -.065 \\
\hline
\end{tabular}




\begin{tabular}{|c|c|c|c|c|c|c|c|c|c|c|}
\hline $\begin{array}{l}\text { Effron \& Knowles, 2015a } \\
\text { (Study 4) }\end{array}$ & 868 & GP & USA & C-S & Yes & $\mathrm{AB}$ & Attitudes & Ethnic/racial & Forced & -.050 \\
\hline \multirow{3}{*}{$\begin{array}{l}\text { Effron \& Knowles, 2015a } \\
\text { (Study 5) }\end{array}$} & 83 & Stud & USA & Exp & Yes & $\mathrm{AB}$ & Attitudes & Ethnic/racial & Forced & -.030 \\
\hline & & & & & & $\mathrm{AB}$ & Attitudes & Other & Chosen & -.224 \\
\hline & & & & & & $\mathrm{AB}$ & Attitudes & Other & Chosen & -.044 \\
\hline \multirow{3}{*}{$\begin{array}{l}\text { Effron \& Knowles, 2015a } \\
\text { (Study 6) }\end{array}$} & 503 & GP & USA & Exp & Yes & $\mathrm{AB}$ & Attitudes & Ethnic/racial & Forced & .088 \\
\hline & & & & & & $\mathrm{AB}$ & Attitudes & Other & Chosen & -.086 \\
\hline & & & & & & $\mathrm{AB}$ & Attitudes & Other & Chosen & .087 \\
\hline $\begin{array}{l}\text { Effron \& Knowles, 2015a } \\
\text { (Study 7) }\end{array}$ & 1409 & GP & USA & Exp & Yes & $\mathrm{AB}$ & Attitudes & Religion & Chosen & -.030 \\
\hline Effron, 2015 & 237 & GP & UK & C-S & No & $\mathrm{AB}$ & Emotions & Religion & Chosen & .010 \\
\hline $\begin{array}{l}\text { Effron \& Knowles, 2015b } \\
\text { (study 1) }\end{array}$ & 257 & GP & USA & Exp & No & $\mathrm{AB}$ & Emotions & Ethnic/racial & Forced & -.128 \\
\hline $\begin{array}{l}\text { Effron \& Knowles, 2015b } \\
\text { (study 2) }\end{array}$ & 252 & GP & USA & Exp & No & $\mathrm{AB}$ & Emotions & Ethnic/racial & Forced & .045 \\
\hline \multirow{4}{*}{$\begin{array}{l}\text { Grzesiak-Feldman \& Suszek, } \\
2008\end{array}$} & 63 & Stud & Poland & C-S & Yes & CS & Attitudes & Ethnic/racial & Forced & .530 \\
\hline & & & & & & $\mathrm{CS}$ & Attitudes & Ethnic/racial & Forced & .670 \\
\hline & & & & & & $\mathrm{CS}$ & Attitudes & Ethnic/racial & Forced & .650 \\
\hline & & & & & & $\mathrm{CS}$ & Attitudes & $\begin{array}{l}\text { Sexual } \\
\text { orientation }\end{array}$ & Homo & .380 \\
\hline \multirow[t]{2}{*}{ Gulevich et al., 2016} & 299 & GP & Russia & C-S & Yes & $\mathrm{CS}$ & Attitudes & $\begin{array}{l}\text { Sexual } \\
\text { orientation }\end{array}$ & Homo & .532 \\
\hline & & & & & & $\mathrm{CS}$ & Attitudes & $\begin{array}{l}\text { Sexual } \\
\text { orientation }\end{array}$ & Homo & .494 \\
\hline \multirow[t]{6}{*}{ Haqanee et al., 2014} & 127 & Stud & Canada & C-S & Yes & EB & Attitudes & Mental illness & Forced & .530 \\
\hline & & & & & & EB & Attitudes & Mental illness & Forced & .200 \\
\hline & & & & & & EB & Attitudes & Mental illness & Forced & .410 \\
\hline & & & & & & EB & Attitudes & Mental illness & Forced & .410 \\
\hline & & & & & & EB & Attitudes & Mental illness & Forced & .060 \\
\hline & & & & & & EB & Attitudes & Mental illness & Forced & .010 \\
\hline Haslam et al., 2002 & $\begin{array}{l}47- \\
81\end{array}$ & Stud & Australia & C-S & Yes & EB & Attitudes & Ethnic/racial & Forced & .010 \\
\hline
\end{tabular}




\begin{tabular}{|c|c|c|c|c|c|c|c|c|c|c|}
\hline & & & & & & EB & Attitudes & Ethnic/racial & Forced & .260 \\
\hline & & & & & & EB & Attitudes & Ethnic/racial & Forced & .400 \\
\hline & & & & & & EB & Attitudes & $\begin{array}{l}\text { Sexual } \\
\text { orientation }\end{array}$ & Homo & .530 \\
\hline \multirow{3}{*}{$\begin{array}{l}\text { Hodson \& Skorska, } 2015 \\
\text { (Study 2) }\end{array}$} & 274 & Stud & Canada & $\mathrm{C}-\mathrm{S}$ & Yes & EB & Attitudes & Ethnic/racial & Forced & .520 \\
\hline & & & & & & EB & Attitudes & Mental illness & Forced & .530 \\
\hline & & & & & & EB & Attitudes & $\begin{array}{l}\text { Sexual } \\
\text { orientation }\end{array}$ & Homo & .470 \\
\hline \multirow[t]{3}{*}{ Keller, 2005 (study2) } & 249 & Stud & Germany & $\mathrm{C}-\mathrm{S}$ & Yes & EB & Attitudes & Ethnic/racial & Forced & .270 \\
\hline & & & & & & EB & Attitudes & Ethnic/racial & Forced & .300 \\
\hline & & & & & & EB & Attitudes & Ethnic/racial & Forced & .150 \\
\hline \multirow[t]{3}{*}{ Newheiser \& Dovidio, 2012} & 161 & Stud & USA & C-S & Yes & $\mathrm{CS}$ & Attitudes & Religion & Chosen & .110 \\
\hline & & & & & & $\mathrm{CS}$ & Attitudes & Religion & Chosen & .300 \\
\hline & & & & & & $\mathrm{CS}$ & Attitudes & Religion & Chosen & .420 \\
\hline \multirow{3}{*}{$\begin{array}{l}\text { Newheiser et al., } 2009 \\
\text { (Study1) }\end{array}$} & 71 & Stud & UK & $\mathrm{C}-\mathrm{S}$ & Yes & $\mathrm{CS}$ & Attitudes & Religion & Chosen & .240 \\
\hline & & & & & & $\mathrm{CS}$ & Attitudes & Religion & Chosen & .340 \\
\hline & & & & & & $\mathrm{CS}$ & Attitudes & Religion & Chosen & .480 \\
\hline \multirow{3}{*}{$\begin{array}{l}\text { Newheiser et al., } 2009 \\
\text { (study2) }\end{array}$} & 115 & Stud & UK & $\mathrm{C}-\mathrm{S}$ & Yes & $\mathrm{CS}$ & Attitudes & Ethnic/racial & Forced & .070 \\
\hline & & & & & & $\mathrm{CS}$ & Attitudes & Ethnic/racial & Forced & .280 \\
\hline & & & & & & $\mathrm{CS}$ & Attitudes & Ethnic/racial & Forced & -.250 \\
\hline Ommundsen et al., 2013 & 264 & GP & Norway & $\mathrm{C}-\mathrm{S}$ & Yes & $\mathrm{AB}$ & Attitudes & Religion & Chosen & .420 \\
\hline \multirow[t]{3}{*}{ Phelps et al., 2013} & 529 & Stud & Norway & C-S & Yes & $\mathrm{AB}$ & Attitudes & Ethnic/racial & Forced & .550 \\
\hline & & & & & & $\mathrm{CS}$ & Attitudes & Ethnic/racial & Forced & .320 \\
\hline & & & & & & $\mathrm{CS}$ & Behavior & Ethnic/racial & Forced & .560 \\
\hline \multirow{2}{*}{$\begin{array}{l}\text { Roets \& Van Hiel, } 2011 \\
\text { (Study 1a) }\end{array}$} & 302 & Stud & Belgium & $\mathrm{C}-\mathrm{S}$ & Yes & $\mathrm{CS}$ & Attitudes & Ethnic/racial & Forced & .460 \\
\hline & & & & & & $\mathrm{CS}$ & Attitudes & Ethnic/racial & Forced & .380 \\
\hline \multirow{3}{*}{$\begin{array}{l}\text { Roets \& Van Hiel, } 2011 \\
\text { (Study 1b) }\end{array}$} & 105 & GP & Belgium & $\mathrm{C}-\mathrm{S}$ & Yes & EB & Attitudes & Ethnic/racial & Forced & .560 \\
\hline & & & & & & EB & Attitudes & Ethnic/racial & Forced & .470 \\
\hline & & & & & & EB & Attitudes & Ethnic/racial & Forced & .500 \\
\hline
\end{tabular}




\begin{tabular}{|c|c|c|c|c|c|c|c|c|c|c|}
\hline & & & & & & EB & Attitudes & Ethnic/racial & Forced & .580 \\
\hline & & & & & & $\mathrm{EB}$ & Attitudes & Ethnic/racial & Forced & .500 \\
\hline & & & & & & CS & Attitudes & Ethnic/racial & Forced & .500 \\
\hline \multirow{2}{*}{$\begin{array}{l}\text { Roets \& Van Hiel, } 2011 \\
\text { (Study 3a) }\end{array}$} & 141 & GP & Belgium & $\mathrm{C}-\mathrm{S}$ & Yes & $\mathrm{CS}$ & Attitudes & Ethnic/racial & Forced & .500 \\
\hline & & & & & & CS & Attitudes & Ethnic/racial & Forced & .430 \\
\hline \multirow{2}{*}{$\begin{array}{l}\text { Roets \& Van Hiel, } 2011 \\
\text { (Study 3b) }\end{array}$} & 162 & Stud & Belgium & C-S & Yes & EB & Attitudes & Ethnic/racial & Forced & .560 \\
\hline & & & & & & EB & Attitudes & Ethnic/racial & Forced & .390 \\
\hline Roets, 2015 & 231 & Stud & Belgium & C-S & No & EB & Attitudes & Ethnic/racial & Forced & .579 \\
\hline Rydell et al., 2007 (study1) & 59 & Stud & USA & C-S & Yes & $\mathrm{CS}$ & Attitudes & Other & Chosen & .780 \\
\hline Rydell et al., 2007 (study2) & 94 & Stud & USA & Exp & Yes & $\mathrm{CS}$ & Attitudes & Other & Chosen & .610 \\
\hline \multirow[t]{2}{*}{$\begin{array}{l}\text { Spencer-Rodgers, Hamilton, } \\
\text { et al., } 2007 \text { (study 2) }\end{array}$} & 89 & Stud & Canada & C-S & Yes & $\mathrm{CS}$ & Attitudes & Other & Forced & .420 \\
\hline & & & & & & EB & Attitudes & Other & Chosen & .430 \\
\hline \multirow{2}{*}{$\begin{array}{l}\text { Stenstrom et al., } 2008 \text { (study } \\
\text { 2) }\end{array}$} & 102 & GP & USA & Exp & Yes & $\mathrm{CS}$ & Behavior & Other & Chosen & .270 \\
\hline & & & & & & $\mathrm{CS}$ & Emotions & Other & Chosen & .380 \\
\hline
\end{tabular}

Note. AB - Agency-based entitativity approach; C-S - cross-sectional; CS - Common scale entitativity approach; EB - Essence-based entitativity approach; Exp - experiment; GP - general population; Stud - Students. 